\title{
8
}
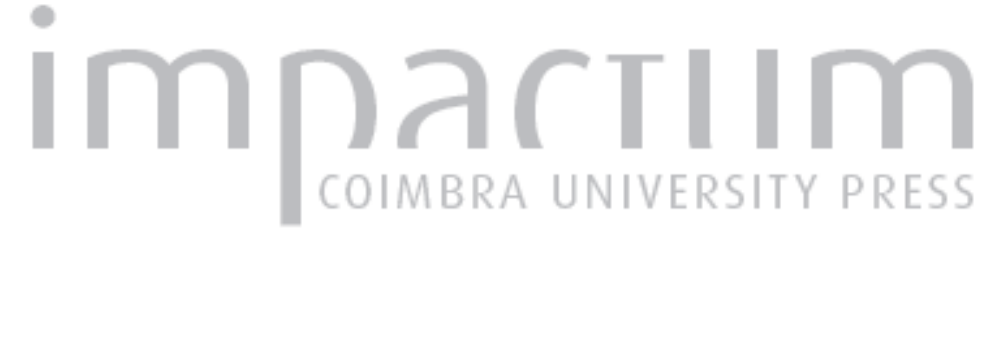

\section{Entre rigor e criatividade ou os limites da tradução literária: entrevista com Frederico Lourenço}

Autor(es): $\quad$ Caldeira, Alexandra; Buggio, Alessandra Publicado por: Associação Portuguesa de Estudos Clássicos; Instituto de Estudos

URL

persistente:

DOI: DOI:http://dx.doi.org/10.14195/0872-2110_53_12

Accessed : $\quad$ 26-Apr-2023 13:50:55

A navegação consulta e descarregamento dos títulos inseridos nas Bibliotecas Digitais UC Digitalis, UC Pombalina e UC Impactum, pressupõem a aceitação plena e sem reservas dos Termos e Condições de Uso destas Bibliotecas Digitais, disponíveis em https://digitalis.uc.pt/pt-pt/termos.

Conforme exposto nos referidos Termos e Condições de Uso, o descarregamento de títulos de acesso restrito requer uma licença válida de autorização devendo o utilizador aceder ao(s) documento(s) a partir de um endereço de IP da instituição detentora da supramencionada licença.

Ao utilizador é apenas permitido o descarregamento para uso pessoal, pelo que o emprego do(s) título(s) descarregado(s) para outro fim, designadamente comercial, carece de autorização do respetivo autor ou editor da obra.

Na medida em que todas as obras da UC Digitalis se encontram protegidas pelo Código do Direito de Autor e Direitos Conexos e demais legislação aplicável, toda a cópia, parcial ou total, deste documento, nos casos em que é legalmente admitida, deverá conter ou fazer-se acompanhar por este aviso.

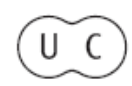




\section{Boletim de \\ Estudos Clássicos}

Associação Portuguesa de Estudos Clássicos Instituto de Estudos Clássicos

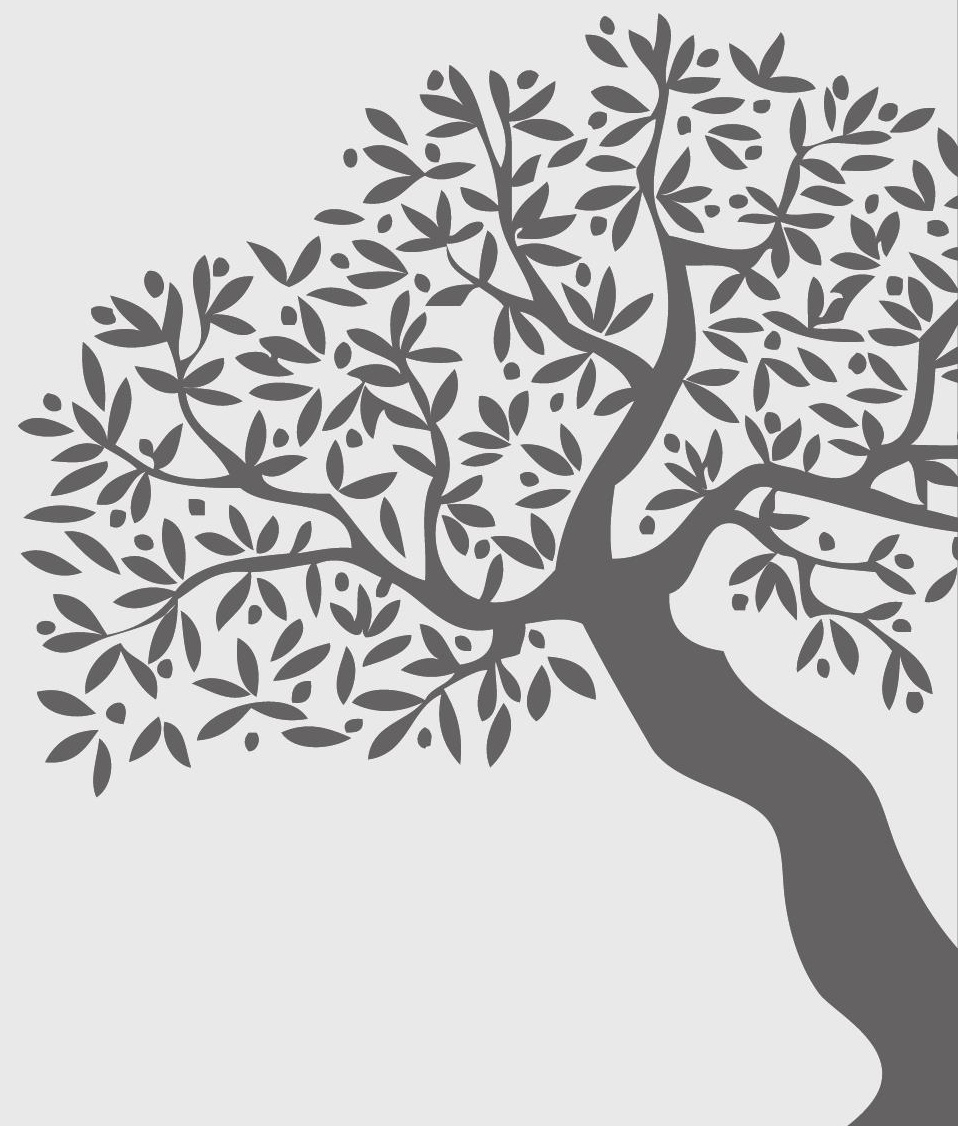

Coimbra

Junho de 2010 


\section{ENTRE RIGOR E CRIATIVIDADE OU OS LIMITES DA TRADUÇÃo LiTERÁRIA. ENTREVISTA COM FREDERICO LOURENÇO}

Helenista de formação, Frederico Lourenço é também tradutor, crítico literário e romancista. Traduziu em verso os poemas homéricos, a Ilíada e a Odisseia, assim como uma antologia de poemas intitulada Poesia Grega de Álcman a Teócrito e outras obras de autores gregos e da literatura alemã. Traduziu textos teatrais como Hipólito e Íon, de Eurípides; Filoctetes, de Sófocles; Don Carlos, de Friedrich Schiller; e Ifigénia na Táurida, de Goethe, alguns dos quais foram representados.

Os Estudos Italianos do Departamento de Línguas, Literaturas e Culturas da FLUC, juntamente com a Secção de Tradução, convidaram o Professor Frederico Lourenço a participar no Seminário Aberto de Tradução Italiano-Português I realizado a 19 de Janeiro de 2010. O Anfiteatro IV esteve repleto de um público interessado e entusiasta, maioritariamente constituído por estudantes de italianística e de tradução. Depois de ter dado uma lição subordinada ao tema 'Entre rigor e criatividade ou os limites da tradução literária', o Professor Frederico Lourenço respondeu a uma série de questões que lhe foi colocada por alunos do Seminário de Tradução ItalianoPortuguês I, por estudantes Erasmus e por alguns investigadores (Alessandra Buggio, Alexandra Caldeira, Angela Latorraca, Clelia Bettini, Davide Di Prete) e que aqui se transcreve.

- Gostaria de trabalhar com um encenador que actualiza o texto teatral clássico, como fez, por exemplo, Luca Ronconi (com Prometeu Agrilhoado, de Ésquilo ou com As Bacantes, de Eurípides, em 2003) no âmbito das representações de Siracusa?

Frederico Lourenço: Se eu fosse tradutor de uma obra para ser encenada, naturalmente, que seria muito mais criativo do que rigoroso. Aliás, isso foi algo que me aconteceu já com o trabalho que fiz com Luís Miguel Cintra. Dar largas à criatividade, enquanto tradutor, só vem favorecer o trabalho de tradução. Eu próprio comecei por ser um tradutor rigoroso e passei depois a assumir-me como um tradutor mais recreativo. 
Contudo, em certas circunstâncias, entendo mesmo que temos de deixar de ser tão pós-modernos e passar a ser um pouco mais rigorosos no que diz respeito à obra. Mas também há autores que são melhores de traduzir do que outros. Há autores que ficam sempre bem na fotografia por serem tão ricos, como Homero. Está lá tudo no texto, por isso mesmo são fáceis de traduzir por qualquer tradutor. Há, de facto, autores que são mais gratos de traduzir do que outros por todas estas razões.

- Gostaria que nos explicasse, mais concretamente, porque define ou caracteriza a sua versão de Filoctetes, de Sófocles, como uma recriação poética e não uma tradução. Afinal, o texto de base já era poético; então, porque insiste dizendo que é recriação poética? O que é isso da recriação poética de que tanto fala?

F.L.: É uma recriação porque decidi fazer uma pequena adaptação ao teatro da tragédia grega e procurei encontrar maneiras mais interessantes de recriar o texto original. É um pouco a ideia contida na metáfora feather duster situation (estratégia muito utilizada nas representações teatrais para rapidamente situar o público no tempo e no espaço), uma vez que procurei tirar um pouco desse pó da obra Filoctetes, de Sófocles, o que não foi necessário fazer em relação à tradução das duas obras de Homero pela sua genialidade ser tão absoluta.

- Verificámos que fez duas versões da Odisseia, de Homero: uma para jovens e outra integral. Os seus percursos de tradutor de teatro também são diversos. Qual é o papel do leitor nas opções que faz enquanto tradutor?

F.L.: Por norma, tento sempre recriar algo que seja interessante para o leitor, a tal ponto que tenho sempre presente como é que o leitor/público que vai ler as minhas traduções vai reagir a essa leitura. O leitor/destinatário é, de facto, muito importante. Esse é, na minha opinião, um dos maiores problemas dos tradutores do século XIX, que eram absolutamente autistas e não pensavam no seu público.

- Nos últimos tempos tem editado muitas traduções com a editora Cotovia. De que forma o editor interage com os seus projectos de tradução e/ou vice-versa? Porque não há, por exemplo, edições bilingues das suas traduções?

F.L.: Sou defensor de que seria até um incentivo poder acompanhar a leitura das minhas obras em duas línguas numa mesma edição: grego e 
português. Mas a editora Cotovia foi absolutamente irredutível quanto a esse aspecto. Penso que por motivos de ordem económica. Não faço traduções por encomenda, por isso, esse problema que referiu na pergunta não se põe.

- A sua tradução da Odisseia, de Homero, foi verdadeiramente inovadora, uma vez que foi a primeira em verso em língua portuguesa. $\mathrm{O}$ que pensa da eterna questão de que só os poetas podem traduzir poesia?

F.L.: Acredito, sem dúvida, que só um poeta pode traduzir um poema. O que procurei fazer, contudo, foi manter o rigor da letra do texto original, por outras palavras, manter-me fiel ao espírito e à letra originais, o que levou a que nem sempre conseguisse reproduzir o ritmo. Era de todo impossível manter o ritmo dos 16000 versos da Ilíada e dos 12000 da Odisseia, porque teriam que se omitir frases ou expressões. A necessidade de respeitar a letra da Ilíada e da Odisseia levou a que as minhas traduções resultassem muito prosaicas e muito pouco líricas. Por isso, não é muito correcto afirmar-se que fiz uma tradução em poesia dessas duas grandes obras. $\mathrm{O}$ que fiz não é bem em verso.

- Qual é a importância do trabalho filológico para o tradutor, não unicamente dos clássicos? Refiro-me, nomeadamente, às ferramentas linguísticas e ao trabalho de pesquisa sobre a obra-projecto de tradução.

F.L.: Em relação às traduções que fiz de Eurípides, em contraste com as traduções que fiz de Homero, as primeiras são mais filológicas, porque tive de consultar muito mais obras. Na tradução da Odisseia e da Ilíada, deixeime levar mais pelo ritmo das obras, efectuando consultas só quando tinha dúvidas, se não, se tivesse feito mais consultas, ainda hoje estaria a traduzir a Odisseia, por exemplo. Quanto à Ilíada, a minha tradução procurou o rigor; procurou recriar uma língua que fosse parecida com a língua de Homero, em português. Na verdade, há muito poucas pessoas que sabem ler em grego, daí que reconheça o papel de grande utilidade pragmática que lhes cabe dando a ler em português o que está mais próximo do grego. Nesse sentido, foi o que procurei fazer com a tradução destas duas grandes epopeias homéricas, a Odisseia e a Ilíada. Considero que possuo boas bases de conhecimento da língua grega, o que me conferiu alguma segurança filológica na tradução destas duas obras a partir do grego. Contudo, quaisquer que sejam as opções que se façam, entendo que o verdadeiro perfume do texto perde-se sempre muito numa tradução, uma vez que esta nunca é igual ao original. $\mathrm{O}$ ideal 
seria mesmo aprender-se as línguas originais das obras literárias para se poder ler o original.

- Hoje fala-se muito em escrita feminina e escrita masculina. Será que se pode dizer que a tradução tem género?

F.L.: Se o género do tradutor influi na maneira de traduzir é um terreno muito vago. Pessoalmente, acho as minhas traduções bastante femininas.

- La traduzione latina dei poemi omerici ad opera degli umanisti italiani del Rinascimento ebbe importanza fondamentale per la loro diffusione in epoca moderna. Crede che oggi i classici possano avere lo stesso impatto? Che ruolo hanno oggi, secondo lei, le nuove edizioni dei classici latini e greci?

F.L.: A tradução da Ilíada e da Odisseia, de Leôncio Pilato, é muito mais prosaica do que a minha tradução dessas obras. Em Portugal, no século XVII, Homero ainda era lido a partir da tradução de Lorenzo Valla. Talvez em Portugal, nesta altura, haja que apostar mais na tradução de autores mais antigos. No entanto, há certos textos de que não vale a pena fazer novas traduções, por já existirem versões muito boas. É o caso da Ifigénia na Táurida, de Goethe, por ser uma tradução muito rigorosa de João Barrento.

ALEXANDRA CALDEIRA

ALESSANDRA BUGGIO 